\title{
THE ALGORITHM FOR DETERMINING THE COORDINATES OF A POINT IN THREE-DIMENSIONAL SPACE BY USING THE AUXILIARY POINT
}

\author{
Bartlomiej Oszczak ${ }^{1,2}$, Eliza Sitnik ${ }^{3}$ \\ ${ }^{1}$ University of Warmia and Mazury \\ Department of Satellite Geodesy and Navigation \\ ${ }^{2}$ Air Force Academy \\ Department of Aircraft Navigation \\ ${ }^{3}$ University of Warmia and Mazury \\ Department of Safety Engineering \\ email: bartlomiej.oszczak@kgsin.pl
}

\begin{abstract}
During the process of satellite navigation, and also in the many tasks of classical positioning, we need to calculate the corrections to the initial (or approximate) location of the point using precise measurement of distances to the permanent points of reference (reference points). In this paper the authors have provided a way of developing Hausbrandt's equations, on the basis of which the exact coordinates of the point in two-dimensional space can be determined by using the computed correction to the coordinates of the auxiliary point. The authors developed generalised equations for threedimensional space introducing additional fixed point and have presented proof of derived formulas.
\end{abstract}

Keywords: positioning, surveying, GPS, GNSS, navigation, auxiliary point, corrections.

\section{INTRODUCTION}

Polish geodesists have significant achievements in development of methods and algorithms for solving multiple angular, angular-linear and linear intersections. The professor Stefan Hausbrandt gave the solution to determine corrections to the approximate coordinates of a point, using cracovian notation (Banachiewicz, 1959), on the basis of knowledge or the measurement of two distances connecting the determined point with the fixed points. If the coordinates of the point are known $O\left(x_{O}, y_{O}\right)$ that are an approximation of the coordinates of the desired point $Q\left(x_{Q}, y_{Q}\right)$, the solution can be obtained using Hausbrandt's formula (Hausbrandt,1970), which can be expressed in matrix notation:

$$
\begin{aligned}
& {\left[\begin{array}{ll}
d x & d y
\end{array}\right]=\frac{1}{2} \boldsymbol{A} *\left[\begin{array}{ll}
\Delta x_{O A} & \Delta y_{O A} \\
\Delta x_{O B} & \Delta y_{O B}
\end{array}\right]^{-1}} \\
& \boldsymbol{A}=\left[\Delta x_{O A}^{2}+\Delta y_{O A}^{2}-A Q^{2}+\left(d x^{2}+d y^{2}\right) \quad \Delta x_{O B}^{2}+\Delta y_{O B}^{2}-B Q^{2}+\left(d x^{2}+d y^{2}\right)\right]
\end{aligned}
$$

where:

$A Q$ - the measured distance between the fixed point $A\left(x_{A}, y_{A}\right)$ and the point $Q\left(x_{Q}, y_{Q}\right)$ to be determined, 
$B Q$ - the measured distance between the fixed point $B\left(x_{B}, y_{B}\right)$ and the point $Q\left(x_{Q}, y_{Q}\right)$ to be determined,

$\left(d x^{2}+d y^{2}\right)$ - the increments (finite) to be added to the coordinates of an auxiliary point $O\left(x_{O}, y_{O}\right)$ to obtain coordinates of a point $Q\left(x_{Q}, y_{Q}\right)$.

Knowing the distances $A Q$ i $B Q$, we calculate the first approximation of the point $Q\left(x_{Q}, y_{Q}\right)$ which is being determined by us, assuming $\left(d x^{2}+d y^{2}\right)=0$, and using the formula (Hausbrandt, 1970), written in matrix form:

$$
\left[\begin{array}{ll}
d x & d y
\end{array}\right]=\frac{1}{2}\left[\begin{array}{ll}
\Delta x_{O A}^{2}+\Delta y_{O A}^{2}-A Q^{2} & \Delta x_{O B}^{2}+\Delta y_{O B}^{2}-B Q^{2}
\end{array}\right]\left[\begin{array}{cc}
\Delta x_{O A} & \Delta y_{O A} \\
\Delta x_{O B} & \Delta y_{O B}
\end{array}\right]^{-1} ;
$$

According to Hausbrandt's advice, after receiving values $d x$ and $d y$, the sum of their squares $\left(d x^{2}+d y^{2}\right)$ is calculated. Then, with the method of iteration, by using the steps for more accurate calculation $\left(d x^{2}+d y^{2}\right)$ and by substituting the value of that expression to the formula (1) we can solve the task having even very inaccurate approximations of the point $O\left(x_{O}, y_{O}\right)$.

\section{THE ALGORITHM FOR DETERMINING THE COORDINATES OF A POINT $Q\left(x_{Q}, y_{Q}, z_{Q}\right)$ IN THREE-DIMENSIONAL SPACE BY USING THE AUXILIARY POINT}

The authors of the paper developed generalised equations for the three-dimensional space based on the extra reference point and have presented proof of derived formulas.

If the coordinates of the point $O\left(x_{O}, y_{O}, z_{O}\right)$ that are approximation of the coordinates of the sought point $Q\left(x_{Q}, y_{Q}, z_{Q}\right)$, the values of corrections can be obtained using the iteration formula (3):

where:

$$
\left[\begin{array}{lll}
d x_{i+1} & d y_{i+1} & d z_{i+1}
\end{array}\right]=\frac{1}{2} \boldsymbol{A}^{T} \boldsymbol{B}^{-1}
$$

$$
\begin{gathered}
\boldsymbol{A}=\left[\begin{array}{c}
\Delta x_{O A}^{2}+\Delta y_{O A}^{2}+\Delta z_{O A}^{2}-A Q^{2}+\left(d x_{i}^{2}+d y_{i}^{2}+d z_{i}^{2}\right) \\
\Delta x_{O B}^{2}+\Delta y_{O B}^{2}+\Delta z_{O B}^{2}-B Q^{2}+\left(d x_{i}^{2}+d y_{i}^{2}+d z_{i}^{2}\right) \\
\Delta x_{O C}^{2}+\Delta y_{O C}^{2}+\Delta z_{O C}^{2}-C Q^{2}+\left(d x_{i}^{2}+d y_{i}^{2}+d z_{i}^{2}\right)
\end{array}\right] ; \\
\boldsymbol{B}=\left[\begin{array}{lll}
\Delta x_{O A} & \Delta y_{O A} & \Delta z_{O A} \\
\Delta x_{O B} & \Delta y_{O B} & \Delta z_{O B} \\
\Delta x_{O C} & \Delta y_{O C} & \Delta z_{O C}
\end{array}\right] ;
\end{gathered}
$$

where:

$A Q$ - the distance between the reference point $A\left(x_{A}, y_{A}, z_{A}\right)$ and the sought point $Q\left(x_{Q}, y_{Q}, z_{Q}\right)$,

$B Q$ - the distance between the reference point $B\left(x_{B}, y_{B}, z_{B}\right)$ and the sought point $Q\left(x_{Q}, y_{Q}, z_{Q}\right)$,

$C Q$ - the distance between the reference point $C\left(x_{C}, y_{C}, z_{C}\right)$ and the sought point $Q\left(x_{Q}, y_{Q}, z_{Q}\right)$,

$\left(d x_{i+1}{ }^{2}+d y_{i+1}{ }^{2}+d z_{i+1}{ }^{2}\right)$-the increments to be added to the coordinates of an auxiliary point $O\left(x_{O}, y_{O}, z_{O}\right)$ to obtain the exact coordinates of the sought point $Q\left(x_{Q}, y_{Q}, z_{Q}\right)$.

$\left(d x_{i}{ }^{2}+d y_{i}{ }^{2}+d z_{i}^{2}\right)$ - are the previous values of the increments. 
Using the iteration method, the first approximation of equation (3) is calculated assuming $d x^{2}=0, d y^{2}=0, d z^{2}=0$. This equation converges rapidly because e.g. in GNSS single point positioning (Hofmann-Wellenhof, 2008) the approximate position is very close to the actual position. After obtaining the values $d x_{i+1}, d y_{i+1}, d z_{i+1}$, we calculate the sum of their squares $d x_{i+1}^{2}+d y_{i+1}^{2}+d z_{i+1}{ }^{2}$.

Generally, the number of iterations depends on the values of distances to the reference points and on the goodness of approximate coordinates of point $O\left(x_{o}, y_{o}, z_{o}\right)$ :

$$
X_{Q}=X_{O}+d x_{i+1} ; Y_{Q}=Y_{O}+d y_{i+1} ; Z_{Q}=Z_{O}+d z_{i+1}
$$

If, on the other hand, when:

$$
\begin{aligned}
& d x=x_{Q}-x_{O}=\text { the number is small } \\
& d y=y_{Q}-y_{O}=\text { the number is small } \\
& d z=z_{Q}-z_{O}=\text { the number is small, }
\end{aligned}
$$

we have an approximate formula, that comes from the assumption that $\left(d x^{2}+d y^{2}+d z^{2}\right)=0:$

where:

$$
\left[\begin{array}{lll}
d x & d y & d z
\end{array}\right]=\frac{1}{2} \boldsymbol{A}^{T} \boldsymbol{B}^{-1}
$$

$$
\begin{gathered}
\boldsymbol{A}=\left[\begin{array}{c}
\Delta x_{O A}^{2}+\Delta y_{O A}^{2}+\Delta z_{O A}^{2}-A Q^{2} \\
\Delta x_{O B}^{2}+\Delta y_{O B}^{2}+\Delta z_{O B}^{2}-B Q^{2} \\
\Delta x_{O C}^{2}+\Delta y_{O C}^{2}+\Delta z_{O C}^{2}-C Q^{2}
\end{array}\right] ; \\
\boldsymbol{B}=\left[\begin{array}{lll}
\Delta x_{O A} & \Delta y_{O A} & \Delta z_{O A} \\
\Delta x_{O B} & \Delta y_{O B} & \Delta z_{O B} \\
\Delta x_{O C} & \Delta y_{O C} & \Delta z_{O C}
\end{array}\right]
\end{gathered}
$$

\section{PROOF}

Formulas (3), (4), (5) can be derived in the following way:

If $d x, d y, d z$ are increments which are to be added to the coordinates of the auxiliary point $O\left(x_{O}, y_{O}, z_{O}\right)$ in order to calculate the coordinates of the sought point $Q\left(x_{Q}, y_{Q}, z_{Q}\right)$ the following relations must occur:

$$
\begin{aligned}
& \left(\Delta x_{A O}+d x\right)^{2}+\left(\Delta y_{A O}+d y\right)^{2}+\left(\Delta z_{A O}+d z\right)^{2}=A Q^{2} \\
& \left(\Delta x_{B O}+d x\right)^{2}+\left(\Delta y_{B O}+d y\right)^{2}+\left(\Delta z_{B O}+d z\right)^{2}=B Q^{2} \\
& \left(\Delta x_{C O}+d x\right)^{2}+\left(\Delta y_{C O}+d y\right)^{2}+\left(\Delta z_{C O}+d z\right)^{2}=C Q^{2}
\end{aligned}
$$

When expanded we have:

$$
\begin{aligned}
& \Delta x_{O A}^{2}+d x^{2}-2 \Delta x_{O A} d x+\Delta y_{O A}^{2}+d y^{2}-2 \Delta y_{O A} d y+\Delta z_{O A}^{2}+d z^{2}-2 \Delta z_{O A} d z=A Q^{2} \\
& \Delta x_{O B}^{2}+d x^{2}-2 \Delta x_{O B} d x+\Delta y_{O B}^{2}+d y^{2}-2 \Delta y_{O B} d y+\Delta z_{O B}^{2}+d z^{2}-2 \Delta z_{O B} d z=B Q^{2} \\
& \Delta x_{O C}^{2}+d x^{2}-2 \Delta x_{O C} d x+\Delta y_{O C}^{2}+d y^{2}-2 \Delta y_{O C} d y+\Delta z_{O C}^{2}+d z^{2}-2 \Delta z_{O C} d z=C Q^{2}
\end{aligned}
$$

In the treatment of the relations as the system of linear equations with the unknown quantities $d x, d y, d z$, we have (3) (4) (5): 


$$
\left[\begin{array}{lll}
d x & d y & d z
\end{array}\right]=\frac{1}{2} \boldsymbol{A}^{T} \boldsymbol{B}^{-1}
$$

where:

$$
\begin{gathered}
\boldsymbol{A}=\left[\begin{array}{l}
\Delta x_{O A}^{2}+\Delta y_{O A}^{2}+\Delta z_{O A}^{2}-A Q^{2}+\left(d x^{2}+d y^{2}+d z^{2}\right) \\
\Delta x_{O B}^{2}+\Delta y_{O B}^{2}+\Delta z_{O B}^{2}-B Q^{2}+\left(d x^{2}+d y^{2}+d z^{2}\right) \\
\Delta x_{O C}^{2}+\Delta y_{O C}^{2}+\Delta z_{O C}^{2}-C Q^{2}+\left(d x^{2}+d y^{2}+d z^{2}\right)
\end{array}\right] \\
\boldsymbol{B}=\left[\begin{array}{lll}
\Delta x_{O A} & \Delta y_{O A} & \Delta z_{O A} \\
\Delta x_{O B} & \Delta y_{O B} & \Delta z_{O B} \\
\Delta x_{O C} & \Delta y_{O C} & \Delta z_{O C}
\end{array}\right]
\end{gathered}
$$

If, however, we assume that the approximate point $O\left(x_{O}, y_{O}, z_{O}\right)$ is very close to the sought point $C\left(x_{C}, y_{C}, z_{C}\right)$, we can apply the formula analogous to the formula (8).

The derivation of the formula (8) can be easily extended for calculation of the GNSS point coordinates $Q\left(x_{Q}, y_{Q}, z_{Q}\right)$ and the receiver clock error $c d t$. This solution was derived by Oszczak B. (Oszczak B.,2011), as follows:

$$
\left[\begin{array}{c}
d x \\
d y \\
d z \\
c d t
\end{array}\right]^{T}=\frac{1}{2}\left[\begin{array}{l}
\Delta x_{O A}^{2}+\Delta y_{O A}^{2}+\Delta z_{O A}^{2}-\rho_{A}^{2}+\left(d x^{2}+d y^{2}+d z^{2}+(c d t)^{2}\right) \\
\Delta x_{O B}^{2}+\Delta y_{O B}^{2}+\Delta z_{O B}^{2}-\rho_{B}^{2}+\left(d x^{2}+d y^{2}+d z^{2}+(c d t)^{2}\right) \\
\Delta x_{O C}^{2}+\Delta y_{O C}^{2}+\Delta z_{O C}^{2}-\rho_{C}^{2}+\left(d x^{2}+d y^{2}+d z^{2}+(c d t)^{2}\right) \\
\Delta x_{O D}^{2}+\Delta y_{O D}^{2}+\Delta z_{O D}^{2}-\rho_{D}^{2}+\left(d x^{2}+d y^{2}+d z^{2}+(c d t)^{2}\right)
\end{array}\right]^{T}\left[\begin{array}{cccc}
\Delta x_{O A} & \Delta y_{O A} & \Delta z_{O A} & -\rho_{A} \\
\Delta x_{O B} & \Delta y_{O B} & \Delta z_{O B} & -\rho_{B} \\
\Delta x_{O C} & \Delta y_{O C} & \Delta z_{O C} & -\rho_{C} \\
\Delta x_{O D} & \Delta y_{O D} & \Delta z_{O D} & -\rho_{D}
\end{array}\right]^{-1}
$$

where:

$\rho_{A}-$ the pseudorange measured by the GNSS receiver to the satellite A, $\rho_{\mathrm{B}}-$ the pseudorange measured by the GNSS receiver to the satellite $\mathrm{B}$, $\rho_{C}-$ the pseudorange measured by the GNSS receiver to the satellite $C$, $\rho_{\mathrm{D}}-$ the pseudorange measured by the GNSS receiver to the satellite D.

\section{CONCLUSIONS}

Generalised Hausbrandt's equations, proposed by the authors in this paper and expressed in three-dimensional space can be used in positioning e.g. GNSS (J.B. Tsui, 2000), indoor navigation (B.P. Lukas, 2011), and in other systems (P.D. Groves, 2013), or during the process of stadiometric navigation, as well as in the many tasks of surveying (Ciecko A. et. al., 2006), when we need to calculate the corrections to the initial (or approximate) location of the point on the basis of measured distances to the points of reference. In the presented method these corrections are the functions of the values of distances. In modern satellite navigation (Felski, Urbanski, 1997) and satellite geodesy (Hofmann-Wellenhof, 2008) the initial approximate coordinates of points can be determined using code pseudorange measurements during the navigation process, e.g. data obtained from NMEA 0183 format, while distances can be provided with the help of precise carrier phase measurements. Moreover, during the bathymetric survey, we can use EDM (Electronic Distance Meter) to measure distances precisely to the reference points. In other applications, the approximate position of observer can be known from Inertial Measurement Unit (Susi et. al., 2011) or from different sensors in indoor navigation. 


\section{REFERENCES}

Banachiewicz T. Rachunek krakowianowy, PWN, Warszawa. 1959.

Ciecko A., Oszczak B., Oszczak S.. Drive-by DTM: GPS and GSM Power Cost-Effective Terrain Modeling. Vol. 17., GPS World, 2006.

Felski A., Urbański J. Satelitarne systemy nawigacji i bezpieczeństwa żeglugi, AMW, Gdynia 1997.

Gleason, Scott and Demoz Gebre-Egziabher. GNSS Applications and Methods. Boston. Artitech House, 2009.

Groves P.D. Principles of GNSS, inertial, and multi-sensor integrated navigation systems. Second Edition, Artech House, 2013.

Hausbrandt S. Rachunek wyrównawczy i obliczenia geodezyjne, Tom I. Państwowe Przedsiębiorstwo Wydawnictw Kartograficznych, Warszawa, 1970.

Hofmann-Wellenhof B., Lichtenegger H., Wasle E. GNSS Global Navigation Satellite Systems, GPS, Glonass, Galileo\&more, SpringerWienNewYork, 2008.

Hoffmann-Wellenhof B., Lichtenegger H., Collins J. Global Positioning System. Theory and Practise. SpringerWienNewYork, 2001.

B. P. Lukas. Robust Indoor Positioning through Adaptive Collaborative Labeling of Location Fingerprints. ETH, Zurich, 2011.

NMEA 0183. National Marine Electronics Association. Standard for Interfacing Marine Electronics Devices, 2002.

Oszczak B. New algorithm for GNSS positioning Using System of Linear Equations, ION GNSS+ 2013 CD-ROM Proceedings, November, 2013.

Oszczak B.. Methods of Point Indicators, manuscript, unpublished, Olsztyn, 2011.

Rueger J.M. Electronic Distance Measurement, Springer-Verlag, Berlin, 1996.

Specht C. System GPS, Wydawnictwo Bernardinum, Pelplin, 2007.

Susi M., Borio D., Lachapelle G. Accelerometer signal features and classification algorithms for positioning applications. Proceedings of the 2011 Int. Technical Meeting of the Institute of Navigation. Web, 2011.

J.B. Tsui. Basic equations for finding user position. Fundamentals of Global positioning system receivers. A software approach. Ed. John Wiley \& Sons, 2000, pp. 10-11.

Received: 2013-08-27,

Reviewed: 2013-10-22, by W. Prószyński,

Accepted: 2013-11-19. 